\title{
A Principal Component Analysis of Skills and Competencies Required of Quantity Surveyors: Nigerian Perspective
}

DOI 10.5592/otmcj.2014.2.4 Research paper

\section{Keywords}

Principal component, Factor Analysis, Skill, Competence, Quantity surveyors, Profession, Nigeria

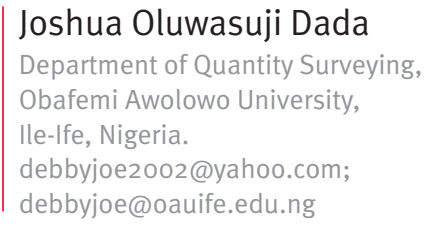

THE PURPOSE OF THIS PAPER IS TO EXAMINE THE INTRINSIC RELATIONSHIPS AMONG SETS OF QUANTITY SURVEYORS' SKILL AND COMPETENCE VARIABLES WITH A VIEW TO REDUCING THEM INTO PRINCIPAL COMPONENTS. The research adopts a data reduction technique using factor analysis statistical technique. A structured questionnaire was administered among major stakeholders in the Nigerian construction industry. The respondents were asked to give rating, on a 5 point Likert scale, on skills and competencies required of quantity surveyors. Based on the 21 skills and 15 competencies areas, factor analysis was used to explore and detect the underlying relationship among the identified variables. Important measures, such as Bartlett's test of sphericity, Kaiser-Meyer-Olkin measure of sampling accuracy and measure of sampling adequacy were used to test the appropriateness of the factor extraction. The data reduction results in the identification of 5 skill components: managerial, technical, investment and global marketing, information and communication technology and professional practice skills; and 3 competence components: project management, valuation and dispute resolution and cost planning and control. The reduced principal components could serve as a guiding framework for training and distilling the required skills and competencies for quantity surveyors especially in Nigeria working environment. The originality and value of the paper is demonstrated in the use of factor analysis in reducing the complex and multiple categorizations of quantity surveyors' skills and competencies into clearly defined principal components. 


\section{INTRODUCTION}

While skill can be defined as proficiency or ability acquired or developed through training or experience, Stewart and Hamlin (1992) defined competence as something which a person who works in a given occupational area should be able to do. Holmes and Joyce (1993) viewed competence as a description of an action, behaviour or outcomes which a person should be able to demonstrate, or the ability to transfer skills and knowledge to new situations within the occupational area. Babalola (2009) while relating this to quantity surveying profession viewed a competent quantity surveyor as a person who is expected to possess a range of skills, knowledge and understanding and be able to apply these skills and knowledge in a range of context and organization.

Formal measures of skill and competence require definition and classification, type and extent. However, the general literature on quantity surveying skill and competence illustrates a multiplicity of perspectives. A review of the various classifications and definition of skill and competence reveals that they are very much at variance. There is duplication of categorization and overlapping of definitions. Consequently, skill and competence classification and adoption are difficult to compare precisely because of diverse definitions. This study attempts to make a useful contribution in this context. The study, which is a follow up to an exploratory survey that investigated the attributes of quantity surveyors skills and competencies (findings reported in Dada and Jagboro, 2012), used the principal component analysis to explore and detect the underlying relationship among the identified skills and competencies required of quantity surveyors. The study aims at reducing the complex and multiple categorizations of the identified skills and competencies required of quantity surveyors into clearly defined principal components.

\section{Literature review}

\section{Quantity Surveyors' skill and} competence

The RICS (1998) sets out the requirements and competencies for assessment of professional competence by listing the competencies required of quantity surveyors in three categories: basic competence, core competence and optional competencies. The basic skills are common to all construction professionals under RICS structure; the core skills are uniquely required of quantity surveyors, while the optional competencies reflect areas of specialization or future career diversification. The Pacific Association of Quantity Surveyors (PAQS) in response to the urgent need of quantity surveyors to reform, developed and implemented in 2001 eight basic skills requiring all quantity surveyors/cost engineers belonging to the institute in Japan, Malaysia, Singapore, Honk Kong, Australia, New Zealand, Fiji and Sri Lanka to comply with. These are: Quantification/Measurement, Communication Skills, Personal and Interpersonal Skills, Business and Management Skills, Professional Practice, Computer and Information Technology, Construction Technology, Construction Law and Regulation (PAQS, 2001).

Githaiga (2004) grouped the experience of the services that quantity surveyors render into budgeting and estimating. The author further highlighted new areas of diversification where we have opportunity and challenges as: development appraisal, pre-contract cost control, taxation planning, contract administration, disputes, litigation and arbitration, technical auditing, valuation for fire insurance, fire loss adjustment, maintenance management schedule of condition and dilapidation, project management, research and development and overseas works. Nkado and Meyer (2001), in their study, carried out a survey of quantity surveyors' professional practice in South Africa and provided a relative importance of skills and competencies required for quantity surveying services. The results from the study presented a long list of 23 competence areas. Babalola (2009) examined the core competencies of quantity surveyors in cost management and administration of electrical engineering services. This study revealed the relevant competencies expected of quantity surveyors and categorized them in the area of strength, weakness, opportunity and threats. According to Leveson (1996), quantity surveying competencies lie in the financial and contractual control of the building project as well as the development of soft skills. The basic skills form the platform from which a competent quantity surveyor can develop and these are integral part of the various units of competence. Crafford and Smallwood (2007) in their study, based on client perception, came up with thirty three competencies.

From the review carried out, the various studies have, no doubt, contributed significantly to the concept of skill and competence required of quantity surveyors. However, there is no clearly defined focus for these skill and competence requirements. Subsequently, Dada and Jagboro (2012) in their study on an exploratory survey that investigated the attributes of quantity surveyors skills and competencies identified twenty one skills and fifteen competence areas. The identified twenty one skill variables are: computer literacy, building engineering, information technology, economics, measurement/quantification, knowledge of civil/heavy engineering, professional practice, construction law, interpersonal skill, knowledge of mechanical and electrical services engineering, financial skill and leadership skill, communication skill, managerial skill, marketing/business skill, knowledge about international 
trading, investment analysis, mapping/surveying, actuarial science, gas/petrochemical engineering and solid mineral engineering. The identified fifteen competence variables are: cost planning and control, estimating, construction procurement system, contract documentation, contract administration, project management, feasibility and viability studies, valuation, financial management, development economics, risk management, life cycle costing, facility management, arbitration/dispute resolution and economic management of urban infrastructure.

\section{The Concept and Theory of}

Factor Analysis

Factor Analysis is a statistical technique used to identify a relatively small number of factors that can be used to represent relationships among sets of many inter-related variable. Ahadzie (2007) and Owusu and Badu (2009) described it as a useful analytical tool for finding cluster of related variables and thus ideal for reducing a large number of variables into a more easily understood framework. According to $\mathrm{Li}$, (2003), the mathematical model for factor analysis appears somewhat similar to a multiple regression equation where each variable is expressed as a linear combination of factors which are not actually observed. In general, the model for the standardized variable is written as:

$X_{i}=A_{i 1} F_{1}+A_{i 2} F_{2}+\ldots+A_{k} F_{k}+U_{i}$

Where the F's are the common factors, the $U$ unique factor, and the A's are the coefficient used to combine the $\mathrm{k}$ factors. The unique factors are assumed to be uncorrelated with each other and with the common factors. The general expression for the estimate of the $j^{\text {th }}$ factor, $F_{j}$ is

$F_{j}=\sum_{i=1}^{p} W_{j y} X_{i}=W_{j i} X_{1}+W_{j 2} X_{2}+\ldots+W_{j p} X_{p}$ where $\mathbf{W}_{i}$ 's are known as factor score coefficients, and $\mathrm{p}$ is the number of variables.

Factor analysis usually proceeds in four steps: In the first step, the correlation matrix for all variables is computed. Variables that do not appear to be related to other variables can be identified from the matrix and associated statistics. For the second step, factor extraction - the number of factors necessary to represent the data and the method for calculating them is determined and it is called "factor extraction". The third step focuses on transforming the factors to make them more interpretable. The fourth step compute scores for each factor in each case. These scores can then be used in a variety of other analysis (Li, 2003).

\section{Research methodology}

In this research, data reduction principle was used in exploring the underlying relationship among the identified quantity surveyors' skill and competence variables within the Nigeria context. Survey method was used in eliciting necessary data for the study. The designed structure questionnaire was pre-tested to ensure the appropriateness of the questions in terms of rhetoric and understanding of meanings prior to sending out the final draft to the respondents. The respondents' choices of answers ranged on a 5-point Likert scale from least favourable to most favourable.

The study population within the context of the study is a database of relevant stakeholders in the construction industry. The first group was the professional quantity surveyors. The second group comprised the co-professionals and for this group, the views of architects, structural engineers and builders, who were found to have direct dealings with quantity surveyors on construction projects, were obtained. The last group was the client organizations who benefits mostly from the services of quantity surveyors. The database of these three groups constituted the sampling frame for the study. Stratified and random sampling techniques were adopted in the selection of the respondents. In order to determine a suitable sample size for the professionals, the total population was obtained from the list of registered professionals published by the respective professional bodies. In selecting appropriate sample size from the lists, the Mendenhall et al (1971) formula for calculating sample size was used. Currently the total number of registered quantity surveyors, architects, engineers and builders in the study area is 719,672 , 487 and 379 respectively. Substituting these values into the formula gives 257 quantity surveyors, 251 architects, 220 engineers and 195 builders. Random sampling method was thereafter used in selecting the respective numbers. For the client organisations, there is no published list that can be employed. Thus, it was not possible to have an exact sampling frame. As such, purposive sampling method was used in obtaining a sample size of 100 public and private client organisations.

A total numbers of one thousand and twenty three questionnaires were sent out to the respondents based on the determined sample size and a total number of four hundred and forty five completely filled (appropriate for analysis) questionnaire were returned. This represents $46.5 \%$ of the total number of questionnaire administered. This considered adequate considering the submission of Moser and Kalton (1979) that the result of a survey would be taken as biased and of little value if the return rate were lower than 30 40\%. Akintoye and Macleod (1997) also supported the view.

In exploring the underlying relationship among the identified quantity surveyors' skill and competence variables, factor analysis statistical technique was used to categorize the identified variables into principal components. 
Various important measures, such as Bartlett's test of sphericity, KaiserMeyer-Olkin (KMO) measure of sampling accuracy and Measure of Sampling Adequacy (MSA) were used to test the appropriateness of the factor extraction.

\section{Results and Discussions}

\section{Principal Component analysis of} Quantity Surveyors' Skill variables The correlation matrix of the 21 variables constituting the skills required by quantity surveyors is shown in Table 1. Since one of the goals of factor analysis is to obtain factors that help explain this correlation, the variables must be related to each other for the factor model to be appropriate. If the correlation between the variables is small, it is unlikely that they share common factors (Nourisis, 1992). The value of the test statistics for sphericity is large (Bartlett's test of sphericity $=4.370 E_{3}$ ) and the associated significance is small ( $p=0.000)$, suggesting that the population correlation was not an identity matrix. Observation of the correlation matrix show that all the items listed have significant correlation at the $5 \%$ level, suggesting no need to eliminate any of the variables for the principal component analysis. The value of the KMO statistics is 0.858 and it is considered satisfactory for factor analysis. The anti image correlation matrix (Table 2) also showed that the MSA of all the factors lie between the range of 0.309 and 0.626 .

The next steps are factor extraction and rotation, to obtain reduced numbers of factors to represent the 21 variables, in order to achieve easy interpretation. Initial matrix and rotated matrix results are shown in Table 3 and Figure 1.

Sixty six percent of the total variance is attributable to the first five items. The remaining sixteen items together accounts for only $34 \%$ of the variance. Thus, a model with five items may be adequate to represent the skills required of quantity surveyors. The factor grouping based on the varimax rotation is shown in Table 4 . Each variable weighs heavily on to only one of the factors, while the loading on each factor exceeds 0.50. Each component is labeled and interpreted as follows: Component 1 - managerial skill, Component 2 - technical skill, Component 3 - investment and international trading, Component 4 Information and communication technology and Component 5 - Professional practice. The label given to each component was generated based on the interrelated characteristics and coupled with the value of loading.

\section{Component 1 - Managerial Skill}

This principal factor accounts for $17.25 \%$ of the observed total variance and it contains eight items. The items are: marketing/business skill (sig. = 0.595), leadership skill (sig. = 0.770), managerial skill (sig. $=0.793$ ), interpersonal skill (sig. $=0.757$ ), communication skill (sig. $=0.677$ ), mapping/surveying (sig. $=0.508$ ) and construction law (sig. = 0.556). Those that received higher loading are: managerial, interpersonal, leadership and communication skills and are regarded very necessary skills for any profession to thrive in the emerging economy. This findings support the position of Westcott and Burnside (2003) that "management is a key area, which education and training can help to address". In addition to the provision of "technical professional services by quantity surveyors, the increasing development of management consultancy-type services can be seen as a means of providing marketdriven, client focused services which can raise the profile status of quantity surveyors and thereby generate better paid and more profitable work.

\section{Component 2 - Technical Skill}

The second principal factor is labeled "technical skill”. This factor accounts for $16.91 \%$ of the total observed variance and contains five items which are regarded as technical. The items are: civil/heavy engineering (sig. = 0.817 ), mechanical and electrical services engineering (0.802), gas and petrochemical engineering (0.784), solid mineral engineering (0.663) and building engineering (0.643). These are regarded as basic skills needed by a quantity surveyor. Before a quantity can perform the core duty of "measurement", the issues of design and construction technology, site conditions, constructability, knowledge of latest building methods and materials, etc. is very important. The importance of technical skills agrees with the findings by Humphery and Stokes (2000).

\section{Component 3 - Investment and global marketing}

The third principal factor is categorized as investment and global marketing. The factor accounts for $13.84 \%$ of the total observed variance and contain four items. The reported factor loadings for the variables are knowledge about international trading (0.805), investment analysis (0.719), actuarial skill (0.703) and financial skill (0.646). Without difficulty, the component is labeled financial management and international trading. The need to include financial management training in construction education as a requirement of the 21st century business strategy was stressed by Owusu-Manu (2008). This is because, financial management controls are vital to project success or failure. Business and capital market environment are changing rapidly, financial market is becoming global, competition is becoming more intense and the financial communication is becoming more complex.

To meet up with this challenge, quantity surveyors must be vast in any matters that concerns financial management and must have a strategy to operate in the global market environment. 


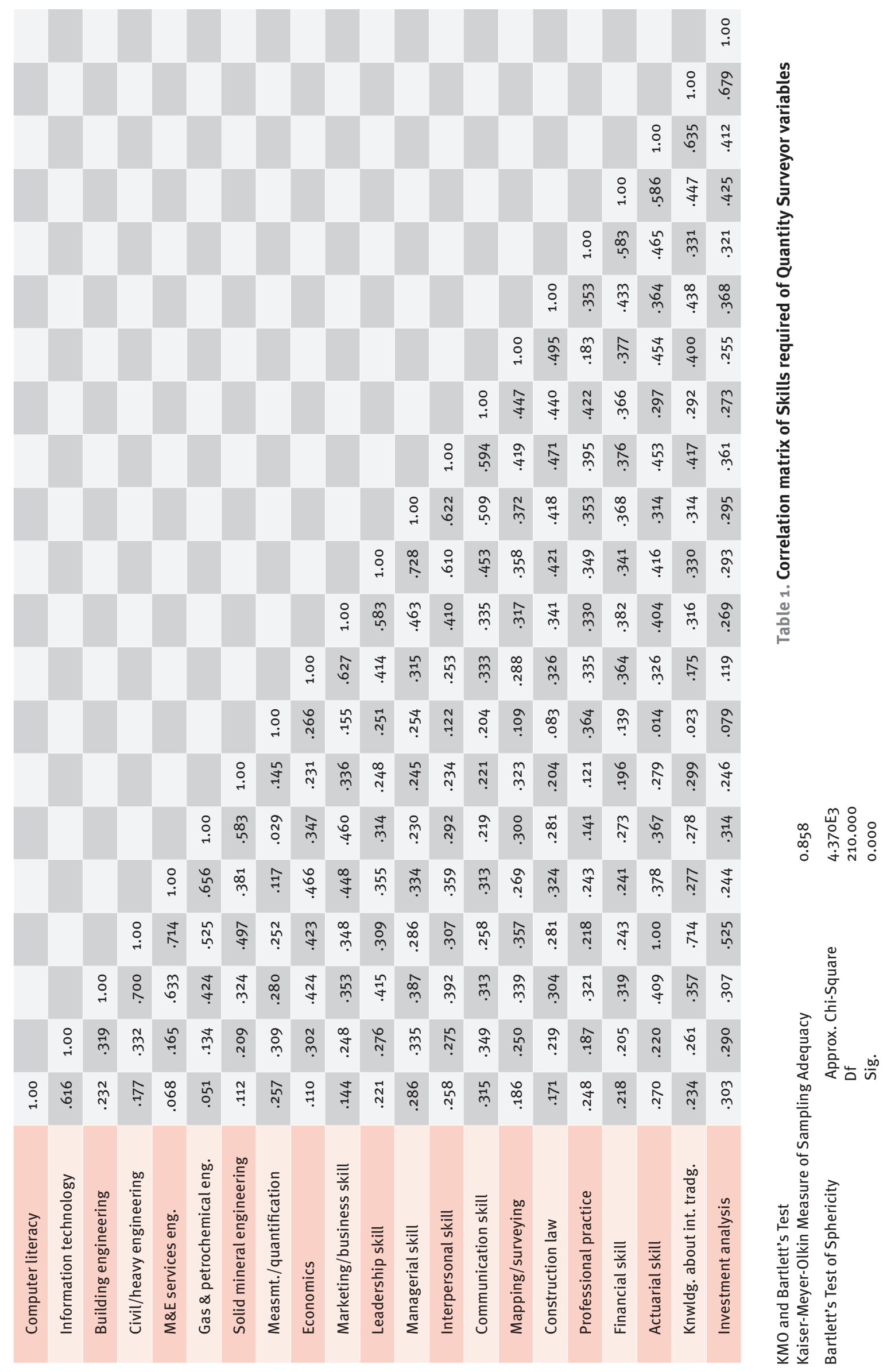




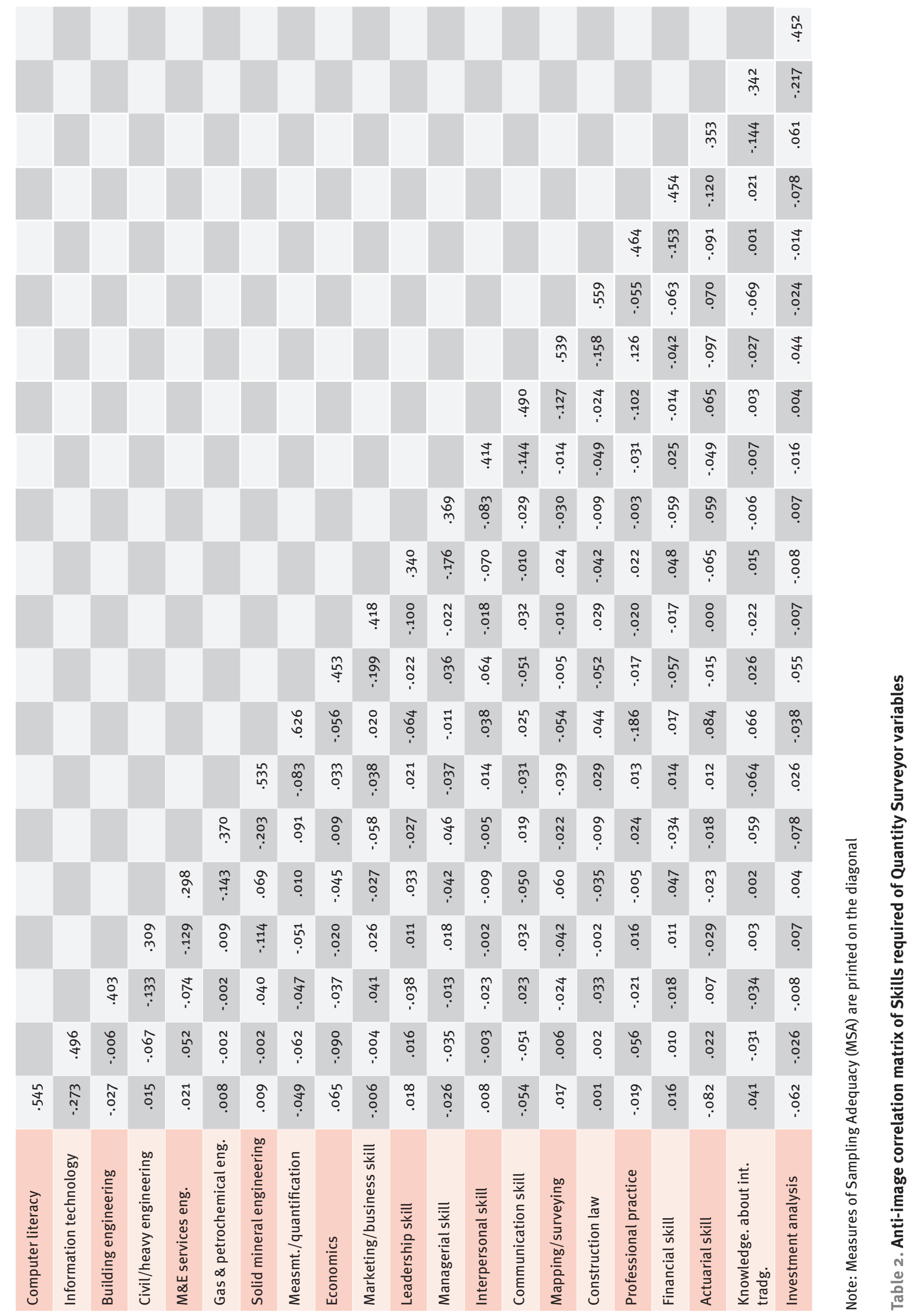




\begin{tabular}{|c|c|c|c|c|c|c|}
\hline \multirow{2}{*}{ Component } & \multicolumn{3}{|c|}{ Initial Eigenvalues } & \multicolumn{3}{|c|}{ Rotation Sums of Squared Loadings } \\
\hline & Total & $\%$ of Variance & Cumulative \% & Total & $\%$ of Variance & Cumulative \% \\
\hline 1 & 7.689 & 36.613 & 36.613 & 3.623 & 17.251 & 17.251 \\
\hline 2 & 1.973 & 9.396 & 46.010 & 3.551 & 16.910 & 34.161 \\
\hline 3 & 1.632 & 7.772 & 53.782 & 2.906 & 13.838 & 47.999 \\
\hline 4 & 1.385 & 6.596 & 60.378 & 1.881 & 8.959 & 56.957 \\
\hline 5 & 1.148 & 5.467 & 65.845 & 1.866 & 8.887 & 65.845 \\
\hline 6 & .878 & 4.181 & 70.026 & & & \\
\hline 7 & .849 & 4.042 & 74.068 & & & \\
\hline 8 & .783 & 3.728 & 77.796 & & & \\
\hline 9 & .673 & 3.206 & 81.002 & & & \\
\hline 10 & .646 & 3.076 & 84.077 & & & \\
\hline 11 & .490 & 2.334 & 86.411 & & & \\
\hline 12 & .420 & 1.999 & 88.410 & & & \\
\hline 13 & .406 & 1.933 & 90.342 & & & \\
\hline 14 & .332 & 1.579 & 91.922 & & & \\
\hline 15 & .307 & 1.462 & 93.383 & & & \\
\hline 16 & .284 & 1.355 & 94.738 & & & \\
\hline 17 & .280 & 1.335 & 96.073 & & & \\
\hline 18 & .250 & 1.189 & 97.262 & & & \\
\hline 19 & .235 & 1.121 & 98.383 & & & \\
\hline 20 & .175 & .834 & 99.217 & & & \\
\hline 21 & .164 & .783 & 100.000 & & & \\
\hline
\end{tabular}

Extraction Method: Principal Component Analysis.

Table 3. Total variance explained of Quantity Surveyors' Skill variables

\section{Component 4 - Information and Communication Technology}

The fourth principal factor is tagged information and communication technology (ICT). This factor is considered very crucial going by the general rating indicated in Table 4. The factor contains two items and accounts for $8.96 \%$ of the total observed variance. The items listed in this principal factor are: computer literacy (sig. $=0.803$ ) and information technology (sig. $=0.793$ ). The rating of computer literacy and information technology is considered appropriate as it is consistent with Nkado and Meyer (2001) survey, which identifies "computer literacy and information technology" as the most important skill required of quantity surveyors. This is also in line with the findings of Humphery and Stokes (2000) and White and Fortune (2002) studies where it was suggested that computer can help a project manager to be more efficient at their job. In fact, 75 percent of Humphery and Stokes' respondents indicated the ability to use computers as being one of the most important set of skills for a project manager to possess. This also supports the findings of Musa et al (2010), that computer literacy and information technology skills will play a major role in the activities of the quantity surveyors in the future. Any quantity surveyor attempting to compete and succeed without these modern tools will be handicapped and their risk of failure will increase.

This suggests that enhanced computer literacy and information technology skills will be an added advantage in the discharge of basic technical competence such as measurement and quantification. Presently, efforts are being shifted to automation in doing things generally. Some services have diminished considerably or are being automated by technology. The reality is that 


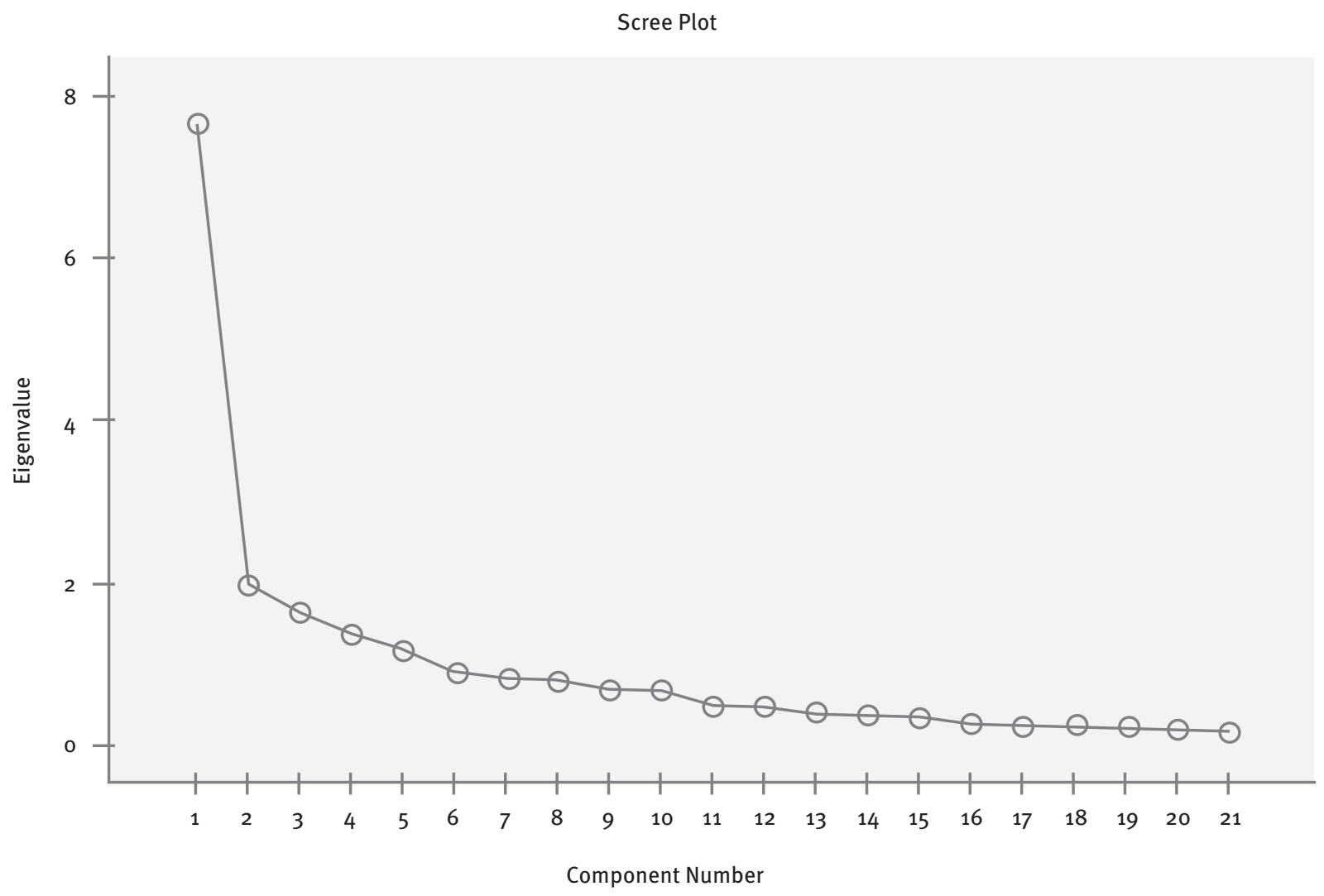

Figure 1. Scree Plot of Skills required of Quantity Surveyor

whatever can be done manually can be automated. The benefit of this cannot be overemphasized in terms of time saving, accuracy and productivity.

\section{Component 5 - Professional practice}

The fifth principal factor is tagged "professional practice" which contains skill such as professional practice (sig. = 0.696), measurement/quantification (sig. $=0.594)$, and economics (sig. = 0.581 ). This factor is also considered very crucial from the indication in the general ranking of skills required by quantity surveyors in Table 4. This principal factor accounts for $8.89 \%$ of the total observed variance. Professional practice can be regarded as the ability to display all the acquired skill by a quantity surveyor and it is therefore considered very important. The inclusion of measurement/quantification is not out of place as measurement constitutes a major skill required by any quantity surveyor.
Principal Component Analysis of Quantity Surveyors' Competence variables

The correlation matrix of the 15 variables constituting the competencies expected of Quantity Surveyors was computed and presented in Table 5. The value of the Kaiser-Meyer-Olkin (KMO) statistic is 0.826 which is satisfactory for factor analysis. Bartlett's test of sphericity tests the hypothesis that the population correlation matrix is not an identity matrix. In this case, the value of the test statistic for sphericity is $3.217 \mathrm{E}_{3}$. The associated significance is small ( $p=$ 0.000 ), which suggest that there is no need to eliminate any of the variables for the principal component analysis. An anti image correlation matrix (Table 6) showed that the MSA of the factors are in the range of $0.228-0.603$ suggesting that they are qualify for the analysis. The next steps are factor extraction and rotation, to obtain reduced numbers of the 15 variables for easy interpretation.
About Sixty three percent of the total variance is attributable to the first three factors. The remaining twelve factors account for about $37 \%$ of the variance. Thus, three model factors were used to represent the data. The factor grouping based on the varimax rotation is shown in Table 8. Each variable weighs heavily on to only one of the factors, while the loading on each factor exceeds 0.50. Each factor grouping has been represented as follows: Component 1- project management, Component 2- Risk management and Component 3- cost planning and control.

Initial matrix and rotated matrix results are shown in Table 7 and Figure 2.

\section{Component 1 - Project Management}

This principal factor accounts for $24.79 \%$ of the total variance and contains six variables. The variables are: estimating (sig. $=0.676$ ), construction procurement systems (sig. $=0.621$ ), 


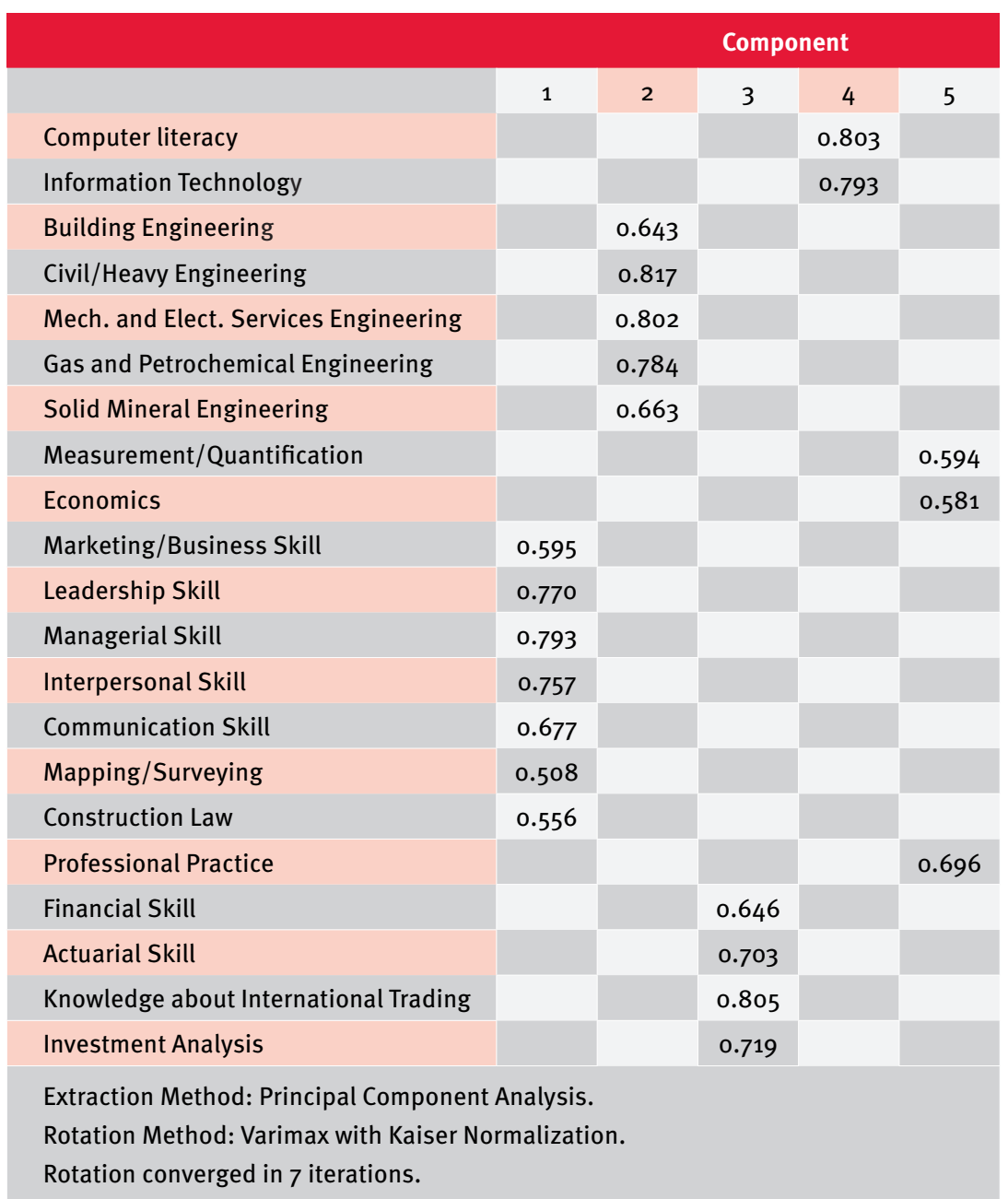

Table 4. Rotated component matrix of Skills required of quantity surveyors

contract documentation (sig. $=0.867$ ), contract administration (sig. $=0.831$ ), project management (sig. $=0.739)$ and financial management (sig. $=0.634)$. The issue of project management is increasingly becoming important. Quoting Dogbegah et al, (2011) “the traditional philosophy of management in construction projects places great emphasis on the ability to plan and execute project". The continued emphasis on project management as the key to organization success is being reinforced; hence, its importance cannot be overemphasized.

\section{Component 2 - Risk Management}

The second principal factor is categorized as risk management. This factor accounts for $22.44 \%$ of the variance and constitutes a major risk to project success and delivery. The inclusion of arbitration and dispute resolution in this principal factor is in consistence with the findings of the study conducted by Dogbegah et al, (2011) on "principal component analysis of project management competencies for the Ghanaian construction industry. In their findings, conflict and dispute management was listed in "project risk and quality management" principal component factor.

\section{Component 3 - Cost Planning and Control}

The third principal factor is labeled “cost planning and control". This factor accounts for $16.11 \%$ of the variance and contains four variables: feasibility/viability studies, development economics, economic management of urban infrastructure and cost planning and control with loading of $0.563,0.610,0.762$ and 0.746 respectively. Cost planning and control is crucial to quantity surveying service. According to Westcott and Burnside (2003), leading edge quantity surveying firms are seeking to take a more pro-active role in the management of costs rather than simply reporting on the costs of design proposals. Cost planning services is therefore seen as one of the core competencies expected of quantity surveyors.

\section{Conclusions}

The multiplicity of perspective in definition and categorization of quantity surveyors' skill and competence has placed great emphasis on the need to explore the underlying and intricate relationship among these skill and competence variables. A review of the various classifications and definition of skill and competence reveals that they are very much at variance. There is duplication of categorization and overlapping of definitions. Consequently, skill and competence classification and adoption are difficult to compare precisely because of diverse definitions. Drawing 


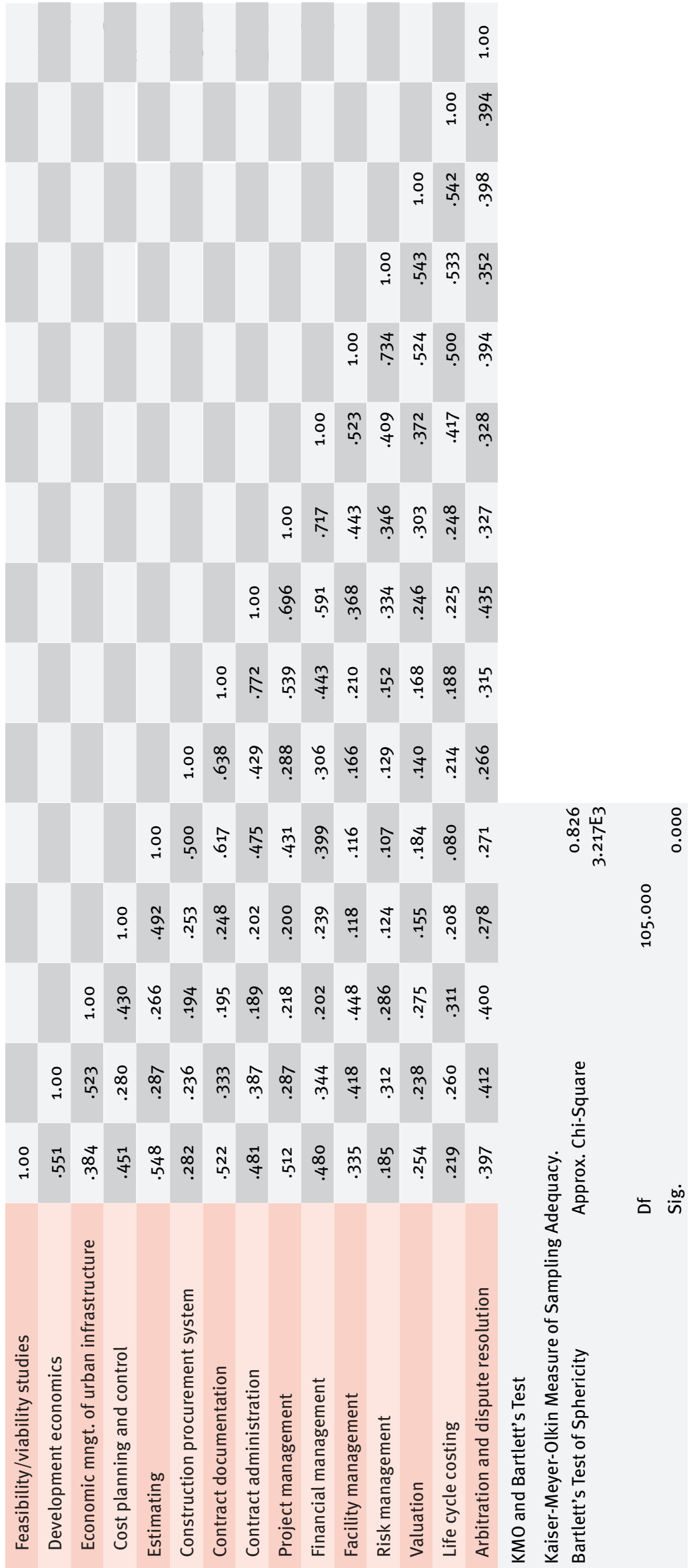

and competencies; factor analysis was used in reducing the identified skills and competencies into more meaningful components. The identified skills were reduced into five principal components, which are, managerial skill, technical skill, investment and global marketing, information and communication technology and professional practice. On the same principle, quantity surveyors competencies were reduced to three principal components. These are: project management, risk management and cost planning and control. The study has provided considerable insight into the issue of quantity surveyors' skill and competence. The study has also contributed to knowledge in the use of factor analysis in reducing the complex and multiple categorizations of quantity surveyors skills and competencies into clearly defined components for easy understanding and interpretation. This brings into fore a quick and simple guiding framework that can be used in training and distilling the required skills and competencies for quantity surveyors in Nigeria working environment. The study has also contributed to knowledge in the use of factor analysis in reducing the complex and multiple categorizations of the identified skills and competencies into clearly defined components.

Table 5. Correlation matrix of Quantity Surveyors' Competencies variables 


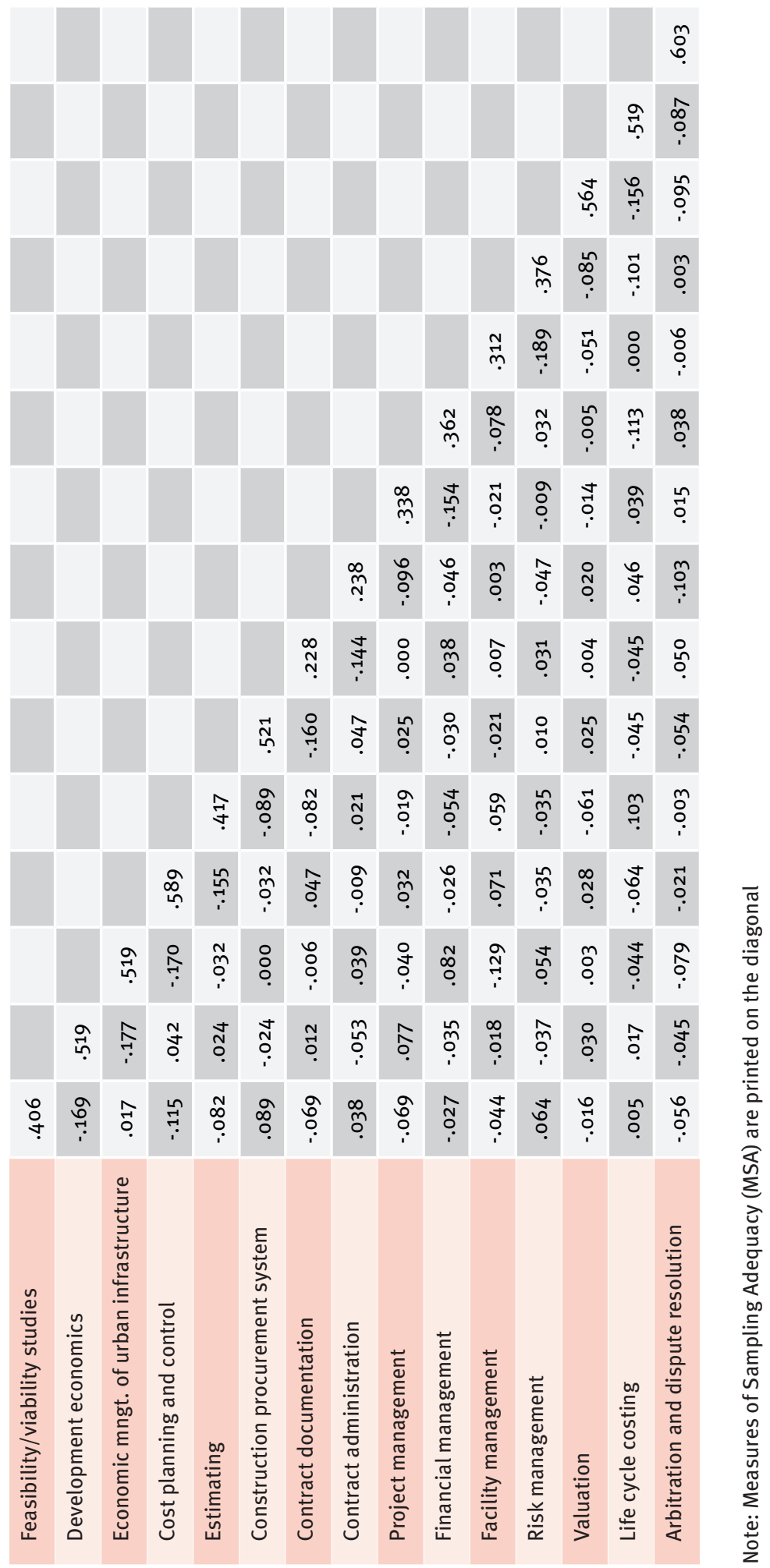

Table 6. Anti-image correlation matrix of Quantity Surveyors' Competencies variables

\section{References}

Ahadzie, D.K. (2007) A model for predicting the performance of project managers in Towards

developing in mass house building projects in Ghana. An unpublished PhD Thesis, University of Wolverhampton, UK.

Akintoye, A.S. and Macleod, M.J. (1997) Risk analysis and management in construction. International Journal of Project Management, 5(1), 31-38.

Babalola, 0. (2009) A study of the core competencies of quantity surveyors in managing electrical and engineering services sub-contract. Journal of Environment Designs and Management, 2 (1), $55-64$.

Crafford, G.J. and Smallwood, J.J. (2007) Clients' views on quantity surveying competencies. Acta structilia: Journal for the physical and development sciences, 14 (1), $33-55$.

Dada, J.O. and Jagboro, G.O. (2012) Core skills requirement and competencies expected of quantity surveyors: perspective from quantity surveyors, allied professionals and client in Nigerian. Australasian Journal of Construction Economics and Building, 12 (4), $78-90$.

Dogbegah, R., Owusu-Manu, D. and Omoteso, K. (2011) A principal component analysis of project management competencies for the Ghanaian construction industry. Australian Journal of Construction Economics and Building, 11 (1), 26-40.

Githaiga, F.M. (2004) Challenges facing the Quantity Surveying Profession in a Globalized

Economy. Proceedings of the 21st Biennial Conference of Nigerian Institute of Quantity Surveyors (NIQS) on "Adding Value to a Reforming Challenges for the Quantity Surveying Profession in Nigeria. 24-27th November, Premier Hotel, Ibadan, Nigeria.

Holmes, L. and Joyce, P. (1993) Rescuing the useful concept of managerial competence: from outcomes back to process, Personnel Review, 22, $37-52$.

Humphery, B. and Stokes, J. (2000) The 21st Century Supervisors: Nine Essential Skills for Frontline Leaders. San Francisco Calif.: Jossey-Bass/Pfeiffer. 


\begin{tabular}{|c|c|c|c|c|c|c|}
\hline \multirow{2}{*}{ Component } & \multicolumn{3}{|c|}{ Initial Eigenvalues } & \multicolumn{3}{|c|}{ Rotation Sums of Squared Loadings } \\
\hline & Total & $\%$ of Variance & Cumulative \% & Total & $\%$ of Variance & Cumulative \% \\
\hline 1 & $5 \cdot 971$ & 39.810 & 39.810 & $3 \cdot 719$ & 24.793 & $24 \cdot 793$ \\
\hline 2 & 2.117 & 14.110 & $53 \cdot 920$ & $3 \cdot 366$ & 22.440 & 47.233 \\
\hline 3 & 1.414 & $9 \cdot 424$ & $63 \cdot 344$ & 2.417 & 16.112 & 63.344 \\
\hline 4 & .938 & 6.257 & 69.601 & & & \\
\hline 5 & .818 & $5 \cdot 452$ & 75.053 & & & \\
\hline 6 & .655 & $4 \cdot 368$ & 79.421 & & & \\
\hline 7 & .533 & 3.550 & 82.971 & & & \\
\hline 8 & .530 & $3 \cdot 531$ & 86.502 & & & \\
\hline 9 & .449 & 2.990 & 89.492 & & & \\
\hline 10 & .393 & 2.621 & 92.113 & & & \\
\hline 11 & .339 & 2.262 & $94 \cdot 375$ & & & \\
\hline 12 & .310 & 2.065 & 96.440 & & & \\
\hline 13 & .233 & 1.552 & 97.992 & & & \\
\hline 14 & .176 & 1.173 & 99.166 & & & \\
\hline 15 & .125 & .834 & 100.000 & & & \\
\hline
\end{tabular}

Extraction Method: Principal Component Analysis.

Table 7. Total variance explained of Quantity Surveyors' Competencies variables

Moser, C.A. and Kalton, G. (1979) Survey Methods in Social Investigation, 2nd Edition. Gower Publishing Company Limited, Aldershot.

Leveson, R. (1996) Can professionals be multiskilled? People Management, 2 (17), 36-39, August.

Li, B. (2003) Risk Management of Construction Public Private Partnership Projects. PhD Thesis, Glasgow Caledonian University, Glasgow.

Mendenhall, W., Ott, L. and Scheaffer, (1971) Elementary Survey Sampling, Woodsworth Publishing Company, Belmont.

Musa, N.A., Babalola, M.O. and Oyebisi, T.O (2010) Competencies Required of Quantity Surveying Profession in Nigeria towards achieving the Millennium Development Goals in the Built Environment. In: Fadare, S.O. and Adeasanya, D.A. (eds.) Sustainable Environment, Faculty of Environmental Design and Management, Obafemi Awolowo University, Ile-Ife, Nigeria, pp. $233-244$
Nkado, R. and Meyer, T. (2001) Competencies of professional quantity surveyors:

South African perspective. Construction

Management and Economics. 19, 481 - 491.

Norusis, M.I. (1992) SPSS for Window, Professional Statistics, Release ${ }_{5}$, SPSS Inc. Chicago, Harmondsworth.

Owusu-Manu, D. (2008) Equipment investment finance strategy for large construction firms in Ghana, an unpublished PhD. Thesis, submitted to the Department of Building Technology, Kwame Nkrumah University of Science and Technology, Kumasi, Ghana.

Owusu-Manu, D. and Badu, E. (2009) Determinants of contractors' investment finance strategy in Ghana: Conceptual and empirical explanations. Journal of Financial Management of Property and Construction, 14 (1) $21-33$.

Pacific Association of Quantity Surveyors (PAQS). (2001) Competency Standard for Quantity Surveyors in the Asian-Pacific Region. Available from http://www. paquantity surveyor.net (Accessed on 02 December 2012)
Royal Institution of Chartered Surveyors (RICS) (1998) The APC Requirement and Competencies, RICS, London.

Stewart, J. and Hamlin, B. (1992) Competencybased qualifications: the case for established methodologies. Journal of European Industrial Training, 16 (17), 21-32.

Westcott, A.J. and Burnside, K. (2003)

Educating for competency in construction economics and management: International Conference of the Institute of surveyors and CASLE on Construction Economics and Management with particular reference to developing countries, 3-5th March, New Delhi.

White, D. and Fortune, J. (2002) Current practice in project management: an empirical study, International Journal of Project Management, 20 (1), 1-11. 
Scree Plot

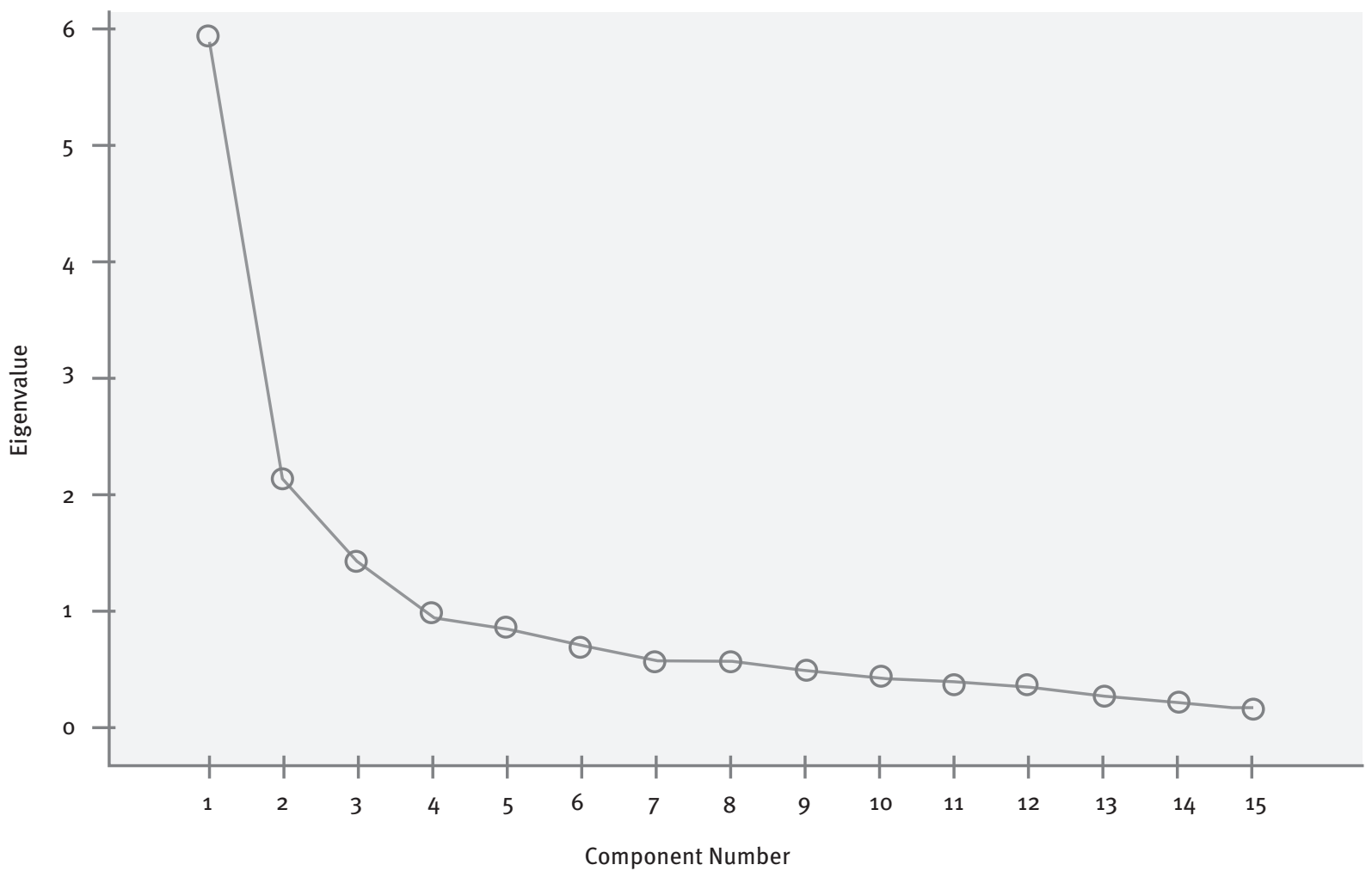

Figure 2. Scree Plot of Skills expected of Quantity Surveyor

\begin{tabular}{|c|c|c|c|}
\hline & \multicolumn{3}{|c|}{ Component } \\
\hline & 1 & 2 & 3 \\
\hline Feasibility/Viability Studies & & & 0.563 \\
\hline Development Economics & & & 0.610 \\
\hline Economic Mngmt. of Urban Infrastructure & & & 0.762 \\
\hline Cost Planning and Control & & & 0.746 \\
\hline Estimating & 0.676 & & \\
\hline Construction Procurement Systems & 0.621 & & \\
\hline Contract Documentation & 0.867 & & \\
\hline Contract Administration & 0.831 & & \\
\hline Project Management & 0.739 & & \\
\hline Financial Management & 0.634 & & \\
\hline Facility Management & & 0.832 & \\
\hline Risk Management & & 0.835 & \\
\hline Valuation & & 0.725 & \\
\hline Life Cycle Costing & & 0.719 & \\
\hline Arbitration and Dispute Resolution & & 0.545 & \\
\hline \multicolumn{4}{|c|}{$\begin{array}{l}\text { Extraction Method: Principal Component Analysis. } \\
\text { Rotation Method: Varimax with Kaiser Normalization. }\end{array}$} \\
\hline Rotation converged in 6 iterations. & & & \\
\hline
\end{tabular}

Table 8. Rotated component matrix of Quantity Surveyors' Competencies variables 